\title{
Phase I, first-in-human trial of programmed cell death receptor-1 (PD-1) inhibitor, JTX-4014, in adult patients with advanced, refractory, solid tumors
}

\author{
Kyriakos P. Papadopoulos ${ }^{1}$ [D $\cdot$ Nehal Lakhani ${ }^{2} \cdot$ Gerald S. Falchook $^{3} \cdot$ Gosia Riley $^{4} \cdot$ Johan Baeck $^{4} \cdot$ Karen S. Brown $^{4}$. \\ Gilad Gordon ${ }^{4} \cdot$ Lidya Le $^{4}$. Judy S. Wang ${ }^{5}$
}

Received: 7 August 2020 / Accepted: 15 September 2020 / Published online: 28 September 2020

(c) The Author(s) 2020

\begin{abstract}
Background Inhibition of programmed cell death receptor protein-1 (PD-1) has proven to be a highly effective strategy for immunotherapy of cancer. Approvals of both PD-1 and PD-L1 inhibitors [PD-(L)1i] in multiple tumor types are evidence of the durable benefits they provide to patients with cancer. In this first-in-human trial, we assessed the safety and tolerability of JTX-4014, a fully human antibody targeting PD-1.

Methods JTX-4014 was administered to 18 patients with multiple solid tumor types who had not previously received a PD(L)1i. The primary objectives were to evaluate the safety and tolerability of JTX-4014 and determine the maximum tolerated dose (MTD) and recommended phase II dose (RP2D). Secondary objectives included evaluation of the pharmacokinetics (PK) of JTX-4014, anti-drug antibodies (ADA) against JTX-4014, and clinical activity.

Results JTX-4014 was well tolerated and no new safety signals were identified as compared with other PD-1is. The MTD was not reached and the RP2D was selected, based on PK modelling and supportive safety data, to be $500 \mathrm{mg}$ every 3 weeks or $1000 \mathrm{mg}$ every 6 weeks. Clinical activity, based on RECIST v1.1 criteria, demonstrated an overall response rate of $16.7 \%$ $(n=3)$ with one complete and two partial responses and a disease control rate of $44.4 \%(n=8)$. The responses occurred at different doses in patients with PD-L1 positive tumors and in tumor types that are not typically PD-1i responsive.

Conclusions Further development of JTX-4014 is warranted as a monotherapy or in combination with other innovative cancer therapies.

Trial registration number NCT03790488, December 312018.
\end{abstract}

Keywords Immunotherapy · Programmed cell death 1 receptor $\cdot$ Investigational therapies $\cdot$ Tumor biomarkers $\cdot$ Salivary gland tumors

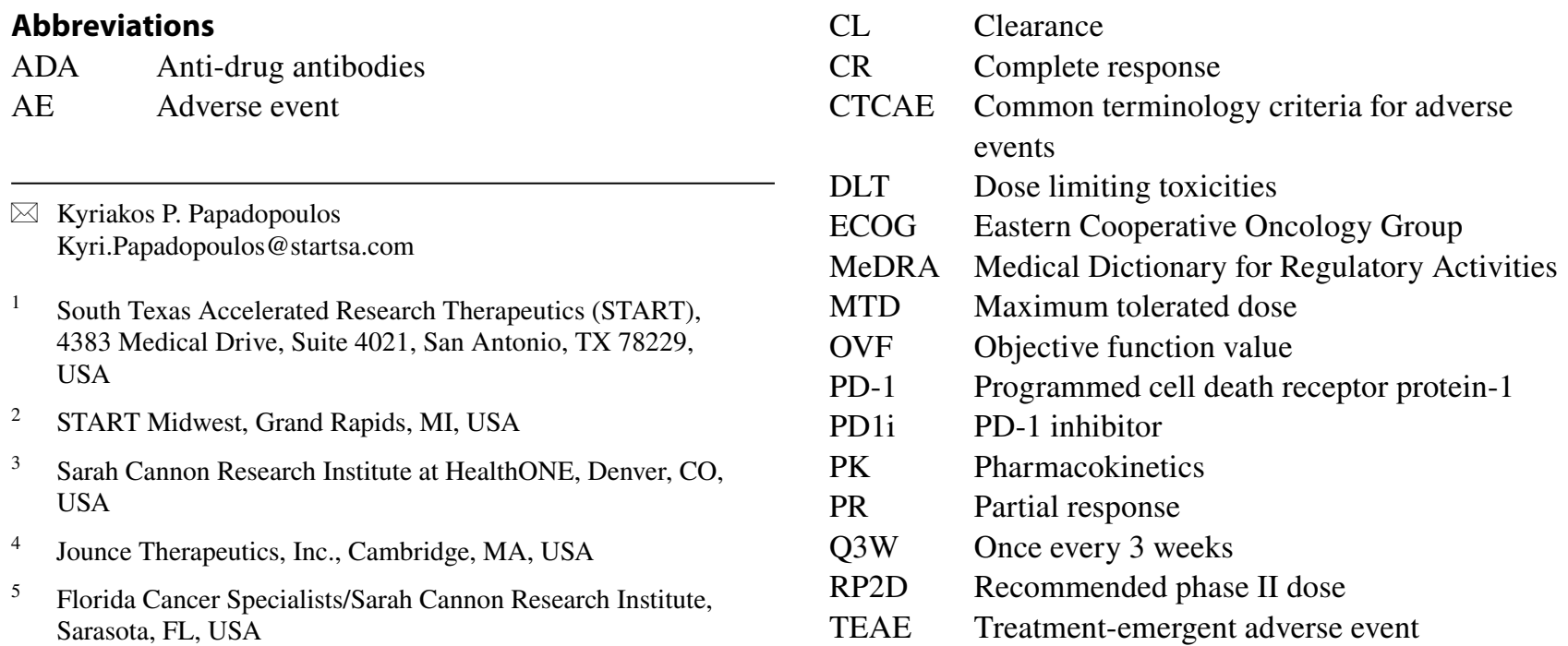




\section{Introduction}

The approvals of PD-1 inhibitors (PD-1is), including pembrolizumab and nivolumab, have caused a paradigm shift in immuno-oncology therapeutics, providing durable remissions for many patients with cancer [1-4]. Patients who achieve objective responses can maintain durable responses for years, demonstrating the potential of the immune system to eradicate or prevent recurrence of cancer $[1,5,6]$. However, response rates to $\mathrm{PD}-1 \mathrm{i}$ monotherapy remain low, prompting investigation of multiple combination therapies across a wide variety of cancers [1, 7-11]. Pembrolizumab and nivolumab dominate the approved immunotherapy treatment landscape, but more PD-1is are needed to support development of innovative combination therapies.

JTX-4014 is a fully human, investigational, anti-PD-1 monoclonal antibody consisting of two identical, hinge-stabilized immunoglobulin gamma 4 heavy chains, and two identical kappa light chains. JTX-4014 specifically binds to PD-1 and augments antitumor activity by blocking the interaction between PD-1 and its ligands, PD-L1 and PD-L2. JTX-4014 is being developed in combination with other therapies for the treatment of cancer in which inhibition of PD-1 may be of benefit. This phase I first-in-human (FIH) trial was designed to evaluate the safety and tolerability of JTX-4014, along with its maximum tolerated dose (MTD) and recommended phase II dose (RP2D), to provide the foundation for future clinical development.

\section{Materials and methods}

\section{Study patients}

Patients were eligible for inclusion if they were $\geq 18$ years, had a histologically or cytologically confirmed solid tumor that was recurrent, metastatic, or refractory to at least one prior line of therapy and had no further standard treatment options. Eligible patients were not on any concurrent anticancer treatment, had received no prior anti-PD-1 or anti-PD-L1 therapy, had an Eastern Cooperative Oncology Group (ECOG) performance status of 0 or 1 , had no history of immune mediated conditions including pneumonitis, were not on active systemic corticosteroid usage $>10 \mathrm{mg} /$ day, and had adequate renal, hepatic, and bone marrow function. Women who were pregnant or lactating were excluded. Of note, positive PD-L1 expression in tumor tissue was not an inclusion criterion.

\section{Study drug}

JTX-4014 was manufactured for Jounce Therapeutics, Inc. by a contract manufacturer and was administered as a $60-\mathrm{min}$ intravenous infusion either once every 3 weeks (Q3W) or once every 6 weeks (Q6W), depending on the cohort.

\section{Trial design}

This phase I, open-label, dose-escalation, FIH study (NCT03790488) was designed to evaluate the safety, tolerability, and pharmacokinetics (PK) of JTX 4014 when administered as a single agent to adult patients with advanced, refractory, solid tumors. The trial was approved by the institutional review boards at each of the four participating sites. The trial design followed a traditional $3+3$ doseescalation design. Dose escalation could only proceed after review of safety and tolerability and dose limiting toxicities (DLT, pre-defined and occurring in the first cycle) with the investigators and sponsor after at least three patients in each cohort completed a 21-day DLT period. Dosing groups were as follows: Cohort 1: $80 \mathrm{mg}$ Q3W; Cohort 2: $240 \mathrm{mg}$ Q3W; Cohort 3a: 800 mg Q3W; Cohort 3b: 800 mg Q6W; Cohort 3c: $400 \mathrm{mg}$ Q3W; and Cohort 4: $1200 \mathrm{mg}$ Q3W. Once a RP2D was determined, patients receiving and tolerating a different dose were eligible to increase their dose to the RP2D, at the discretion of the investigator.

\section{Study objectives}

The primary objectives were to evaluate the safety and tolerability of JTX-4014 and determine the MTD and RP2D. The secondary objectives were to evaluate the PK of JTX-4014 and anti-drug antibodies (ADA) against JTX-4014. Other secondary objectives included clinical activity of JTX-4014 and duration of response.

\section{Pharmacokinetics}

Blood samples for PK were collected pre-dose and at 1 (end of infusion), 24, 48, 168, 336, and 504 hours (h) post-dose for cycle 1 and cycle 3 and pre-dose, and $1 \mathrm{~h}$ post-dose (end of infusion) for cycles 2 and 4 through 9. JTX-4014 concentrations were determined by a validated enzyme-linked immunosorbent assay-based assay. PK parameters following first dose were calculated by non-compartmental analysis using Phoenix WinNonlin ${ }^{\mathrm{TM}}$ Version 8.2 (Certara USA, Inc).

A population pharmacokinetic (PopPK) analysis was performed using a non-linear mixed effects modelling approach and data from 18 patients treated with JTX-4014. Model selection was based on the objective function value (OVF), goodness of fit plots, and scientific plausibility. Body weight was investigated as a covariate of clearance and volume of distribution but was not significant (i.e., it did not result in a reduction in the OFV of 6.63 or more $[P<0.01$, degree of freedom $=1]$ ). Reliability of the model was evaluated based on diagnostic plots, visual predictive checks, and assessment 
of parameter uncertainty. Simulations were performed to characterize exposure profiles for various potential phase II dosing regimens. Interindividual variability random effects on CL, V1 and V2 were included as well as a covariance of $\mathrm{V} 1$ and $\mathrm{V} 2$. A proportional residual error model was employed.

\section{Statistical analysis}

\section{Safety analyses}

Adverse events (AEs) were classified according to the most recent version of the Medical Dictionary for Regulatory Activities (MeDRA) and were graded for severity per common terminology criteria for adverse events (CTCAE) 5.0. Incidence $[\mathrm{N}(\%)]$ of treatment-emergent AEs (TEAEs) are presented by System Organ Class preferred term and CTCAE toxicity grade. PK and immunogenicity data were summarized by descriptive statistics.

\section{Efficacy analyses}

Antitumor activity was assessed both clinically and using imaging (computed tomography scan), unless contraindicated, including optional brain magnetic resonance imaging at screening, and every 9 weeks ( \pm 7 days) after initial dose. Radiological response was assessed by the investigator using RECIST v1.1.

\section{Results}

\section{Patient demographics}

From December 2018 to May 2019, 18 patients were enrolled in the study, and all were included in the final safety and efficacy analyses. As of the data cut-off date, April 15, 2020, 16 patients had discontinued and 2 patients were ongoing. The patients included ten males and eight females, with an average age of 66 years (Table 1). The patients were heavily pre-treated with a median of $3(1-13)$ prior regimens. The most common tumor types enrolled were ovarian $(n=4)$, sarcoma $(n=3)$, mesothelioma $(n=2)$, prostate, $(n=2)$ and salivary gland $(n=2)$.

\section{Safety}

JTX-4014 was well tolerated, resulted in no treatmentrelated deaths or DLTs and had an acceptable safety profile. The MTD was not identified inclusive of the maximum administered dose of $1200 \mathrm{mg} \mathrm{Q3W}$. Sixteen patients experienced 2 or more TEAEs, as shown in Table 2. The most common TEAEs were fatigue $(50.0 \%, n=9)$, aspartate aminotransferase increase $(22.2 \%, n=4)$ and dizziness $(22.2 \%, n=4)$. Of the four patients with dizziness, two events were unrelated to JTX4014 and two were attributed to JTX4014, including in one patient an infusion-related reaction with dizziness.

Seven patients $(38.9 \%)$ experienced a total of 13 Grade $\geq 3$ TEAEs (Table 2). Six of these 13 events occurred in 2 patients at the highest dose of $1200 \mathrm{mg}$ Q3W. All Grade $\geq 3$ TEAEs occurred at a relatively low frequency, with no single Grade 3 TEAE being reported in more than one patient. Only three Grade $\geq 3$ AEs were attributed to the study drug, namely pneumonitis at $1200 \mathrm{mg} \mathrm{Q3W}$, a maculopapular rash at $800 \mathrm{mg} \mathrm{Q3W}$ and an isolated increase in blood alkaline phosphatase at $240 \mathrm{mg}$ Q3W. Pneumonitis, the only drug-related serious AE, occurred after the second dose in a patient with recurrent pleural effusions. This patient presented with bilateral lung opacities and was treated with corticosteroids, with clinical resolution of the event after 3 days. Four patients $(22.2 \%)$ discontinued treatment due to an AE or serious AE, one patient each at $80 \mathrm{mg} \mathrm{Q} 3 \mathrm{~W}$ and $800 \mathrm{mg} \mathrm{Q} 3 \mathrm{~W}$, and two at $1200 \mathrm{mg} \mathrm{Q} 3 \mathrm{~W}$.

\section{Pharmacokinetics}

JTX-4014 exhibited linear PK between 80 and 1,200 mg (Fig. 1), with dose-proportional increases in both maximum concentration $\left(\mathrm{C}_{\max }\right)$ and area under the curve. The mean terminal half-life $\left(\mathrm{T}_{1 / 2}\right)$ ranged from 7 to 14 days and steady state was attained by cycle 7 . The pharmacokinetic characteristics of JTX-4014 were described by a twocompartment model and linear elimination. Inclusion of body weight as a covariate did not result in a statistically significant improvement of the model. The total volume of distribution was estimated to be approximately $6 \mathrm{~L}$. The terminal half-life by PopPK modeling was predicted to be approximately 17 days. No ADAs were detected in any patients as of the data cut-off.

Pharmacokinetic data from 18 patients, comprising 221 JTX-4014 concentrations, were used for the PopPK analysis. As the PK of JTX-4014 was similar to that reported for approved PD-1is (pembrolizumab and nivolumab), simulations were conducted to identify RP2D regimens that would achieve median trough concentrations at steady state $\left(\mathrm{C}_{\text {trough,ss }}\right)$ for JTX-4014, comparable to or greater than the pembrolizumab mean/median $\mathrm{C}_{\text {trough,ss }}$ and the nivolumab geometric mean $\mathrm{C}_{\text {trough,ss }}$. Based on these simulations, two RP2D regimens were identified: $500 \mathrm{mg} \mathrm{Q3W}$ (simulated median [95\% CI] $\mathrm{C}_{\text {trough,ss }}$ of $47.46[22.12,96.51] \mu \mathrm{g} / \mathrm{mL}$, or $1000 \mathrm{mg}$ Q6W (simulated median [95\% CI] $\mathrm{C}_{\text {trough,ss }}$ of $29.70[8.77,71.24] \mu \mathrm{g} / \mathrm{mL})$. 
Table 1 Patient demographics at baseline

\begin{tabular}{|c|c|c|c|c|c|c|c|}
\hline & $\begin{array}{l}\text { Cohort } 1 \\
(80 \mathrm{mg} \text { Q3W) } \\
(n=3)\end{array}$ & $\begin{array}{l}\text { Cohort } 2 \\
(240 \mathrm{mg} \text { Q3W }) \\
(n=3)\end{array}$ & $\begin{array}{l}\text { Cohort 3c } \\
(400 \mathrm{mg} \mathrm{Q} 3 \mathrm{~W}) \\
(n=3)\end{array}$ & $\begin{array}{l}\text { Cohort 3a } \\
(800 \mathrm{mg} \text { Q3W }) \\
(n=3)\end{array}$ & $\begin{array}{l}\text { Cohort 3b } \\
(800 \mathrm{mg} \text { Q6W) } \\
(n=3)\end{array}$ & $\begin{array}{l}\text { Cohort } 4(1200 \mathrm{mg} \\
\text { Q3W) }(n=3)\end{array}$ & $\begin{array}{l}\text { Total } \\
(N=18)\end{array}$ \\
\hline \multicolumn{8}{|l|}{ Sex, $n(\%)$} \\
\hline Male & $2(66.7)$ & $2(66.7)$ & $2(66.7)$ & $1(33.3)$ & $1(33.3)$ & $2(66.7)$ & $10(55.6)$ \\
\hline Female & $1(33.3)$ & $1(33.3)$ & $1(33.3)$ & $2(66.7)$ & $2(66.7)$ & $1(33.3)$ & $8(44.4)$ \\
\hline \multicolumn{8}{|l|}{ Age (years) } \\
\hline Mean (SD) & $69.0(6.00)$ & $60.0(7.94)$ & $73.0(6.24)$ & $65.3(24.42)$ & $69.0(8.72)$ & $61.7(8.96)$ & $\begin{array}{l}66.3 \\
\quad(11.24)\end{array}$ \\
\hline \multicolumn{8}{|l|}{ Ethnicity, $n(\%)$} \\
\hline $\begin{array}{l}\text { Hispanic or } \\
\text { Latino }\end{array}$ & $1(33.3)$ & $1(33.3)$ & 0 & $1(33.3)$ & $1(33.3)$ & 0 & $4(22.2)$ \\
\hline $\begin{array}{l}\text { Not Hispanic or } \\
\text { Latino }\end{array}$ & $2(66.7)$ & $2(66.7)$ & $3(100.0)$ & $2(66.7)$ & $2(66.7)$ & $3(100.0)$ & $14(77.8)$ \\
\hline \multicolumn{8}{|l|}{ Race, $n(\%)$} \\
\hline Asian & 0 & 0 & $1(33.3)$ & 0 & 0 & 0 & $1(5.6)$ \\
\hline White & $3(100.0)$ & $3(100.0)$ & $2(66.7)$ & $3(100.0)$ & $3(100.0)$ & $3(100.0)$ & $17(94.4)$ \\
\hline \multicolumn{8}{|l|}{ Prior therapies } \\
\hline $\begin{array}{l}\text { Median (min, } \\
\max )\end{array}$ & $2.0(1.0,9.0)$ & $4.0(2.0,13.0)$ & $4.0(1.0,5.0)$ & $3.0(1.0,6.0)$ & $3.0(1.0,3.0)$ & $\begin{array}{l}3.0(1.0, \\
6.0)\end{array}$ & $\begin{array}{c}3.0(1.0 \\
13.0)\end{array}$ \\
\hline \multicolumn{8}{|l|}{ ECOG, $n(\%)$} \\
\hline 0 & $1(33.3)$ & $1(33.3)$ & $1(33.3)$ & $1(33.3)$ & $2(66.7)$ & 0 & $6(33.3)$ \\
\hline 1 & $2(66.7)$ & $2(66.7)$ & $2(66.7)$ & $2(66.7)$ & $1(33.3)$ & $3(100.0)$ & $12(66.7)$ \\
\hline \multicolumn{8}{|l|}{ Tumor type, $n(\%)$} \\
\hline Ovary & $1(33.3)$ & 0 & $1(33.3)$ & 0 & $1(33.3)$ & $1(33.3)$ & $4(22.2)$ \\
\hline Sarcoma & 0 & $1(33.3)$ & 0 & $1(33.3)$ & 0 & $1(33.3)$ & $3(16.7)$ \\
\hline Mesothelioma & 0 & $1(33.3)$ & 0 & 0 & $1(33.3)$ & 0 & $2(11.1)$ \\
\hline Prostate & $1(33.3)$ & 0 & 0 & 0 & 0 & $1(33.3)$ & $2(11.1)$ \\
\hline Salivary gland & 0 & 0 & $1(33.3)$ & 0 & $1(33.3)$ & 0 & $2(11.1)$ \\
\hline Other $^{\mathrm{a}}$ & $1(33.3)$ & $1(33.3)$ & $1(33.3)$ & $2(66.7)$ & 0 & 0 & $5(27.8)$ \\
\hline
\end{tabular}

$S D$ standard deviation

${ }^{\text {a}}$ Others included: breast, esophageal, gastric, neuroendocrine carcinoma, and pelvic (1 each)

\section{Clinical activity}

JTX-4014 elicited meaningful responses in this heavily pretreated population (Table 3 and Fig. 2). Based on RECIST v1.1 criteria by investigator assessment, three patients (16.6\%) had confirmed responses, 1 complete response (CR) and 2 partial responses (PRs) (Fig. 3). In addition, five patients (27.8\%) had a best response of stable disease for an overall disease control rate of 8/18 (44.4\%). Six patients (33.3\%) progressed at the time of their first radiological evaluation. The remaining four patients $(22.2 \%)$ discontinued prior to the first radiological evaluation, two due to unrelated AEs, one due to investigator decision and one due to clinical progression. The overall median number of cycles of JTX4014 that was administered was 3.5 (range 1-18).
The three patients who exhibited either a complete or partial response all had evidence of PD-L1 expression on their tumors. Of note, among the remaining 15 patients, 1 patient had PD-L1 staining of $0 \%$ and the rest had no PD-L1 staining available. The patient who had a CR was an 80 -year-old male with a mucoepidermoid carcinoma of the parotid that stained $60 \%$ for PD-L1, who was previously treated with surgery, radiation, and a single previous regimen containing carboplatin and cetuximab (Fig. 3a). His response on $400 \mathrm{mg}$ Q3W was still ongoing at 338 days as of the data cut-off. One of the patients with a PR was a 63-year-old male with carcinoma ex-pleomorphic adenoma that stained $100 \%$ for PD-L1, who was previously treated with surgery, radiation, and three previous regimens, which, in total, consisted of pertuzumab, trastuzumab, leuprolide, carboplatin, paclitaxel, and bicalutamide 
Table 2 Summary of Grade 1/2 TEAEs that occurred in two or more patients and all Grade 3/4 TEAEs

\begin{tabular}{|c|c|c|c|}
\hline Preferred Term & Grade $1 / 2(n=18)$ & Grade $3 / 4(n=18)^{\mathrm{b}}$ & Any grade $(n=18)$ \\
\hline Patients with at least 1 TEAE, n (\%) & $16(88.9)$ & $7(38.9)$ & $16(88.9)$ \\
\hline Fatigue & $9(50.0)$ & 0 & $9(50.0)$ \\
\hline Dizziness & $4(22.2)$ & 0 & $4(22.2)$ \\
\hline Aspartate aminotransferase increase & $4(22.2)$ & 0 & $4(22.2)$ \\
\hline Alanine aminotransferase increase & $3(16.7)$ & 0 & $3(16.7)$ \\
\hline Anemia & $2(11.1)$ & $1(5.6)$ & $3(16.7)$ \\
\hline Tumor pain & $2(11.1)$ & $1(5.6)$ & $3(16.7)$ \\
\hline Edema peripheral & $2(11.1)$ & 0 & $2(11.1)$ \\
\hline Pyrexia & $2(11.1)$ & 0 & $2(11.1)$ \\
\hline Headache & $2(11.1)$ & 0 & $2(11.1)$ \\
\hline Cough & $2(11.1)$ & 0 & $2(11.1)$ \\
\hline Decreased appetite & $2(11.1)$ & 0 & $2(11.1)$ \\
\hline Dehydration & $2(11.1)$ & 0 & $2(11.1)$ \\
\hline Nausea & $2(11.1)$ & 0 & $2(11.1)$ \\
\hline Pruritus & $2(11.1)$ & 0 & $2(11.1)$ \\
\hline Back pain & $2(11.1)$ & 0 & $2(11.1)$ \\
\hline Blood creatinine increased & $1(5.6)$ & $1(5.6)$ & $2(11.1)$ \\
\hline Blood alkaline phosphate increased $^{\mathrm{a}}$ & 0 & $1(5.6)$ & $1(5.6)$ \\
\hline Chronic obstructive pulmonary disease & 0 & $1(5.6)$ & $1(5.6)$ \\
\hline Deafness unilateral & 0 & $1(5.6)$ & $1(5.6)$ \\
\hline Lymphocyte count decreased & 0 & $1(5.6)$ & $1(5.6)$ \\
\hline Metastases to central nervous system & 0 & $1(5.6)$ & $1(5.6)$ \\
\hline Pneumonitis $^{\mathrm{a}}$ & 0 & $1(5.6)$ & $1(5.6)$ \\
\hline Pneumothorax & 0 & $1(5.6)$ & $1(5.6)$ \\
\hline Rash maculo-papular ${ }^{\mathrm{a}}$ & 0 & $1(5.6)$ & $1(5.6)$ \\
\hline Urinary tract obstruction & 0 & $1(5.6)$ & $1(5.6)$ \\
\hline Venous thrombosis & 0 & $1(5.6)$ & $1(5.6)$ \\
\hline
\end{tabular}

TEAE treatment-emergent adverse events

${ }^{\mathrm{a}}$ Grade 3 events attributed by the investigator as related to the study drug

${ }^{\mathrm{b}}$ All Grade 3/4 events are Grade 3 AEs. There were no Grade 4 AEs reported
(Fig. 3b). His response on $800 \mathrm{mg}$ Q6W was still ongoing at 386 days as of the data cut-off. The second patient with a PR was a 68-year-old woman with ovarian cancer that stained $5 \%$ for PD-L1, who was previously treated with surgery and four previous regimens, which, in total, consisted of carboplatin, paclitaxel, gemcitabine, bevacizumab, docetaxel and an investigational agent (Fig. 3c). Time to progression on $400 \mathrm{mg}$ Q3W was 232 days.

Of the five patients who had a best response of stable disease, the mean duration of the stable disease was 230 days (range 127-378 days) with a median of 170 days. One of the patients was noted to have progressive disease (PD) based on radiological findings at day 63 ; however, the patient was felt to have clinical benefit and, per protocol, was maintained on the study and remained stable for a total of 282 days. Per RECIST 1.1, the patient was considered to have PD even though she stayed on trial beyond the first radiological examination.

\section{Discussion}

This FIH trial of a new PD-1i, JTX 4014, demonstrated that the drug was well tolerated, has an acceptable safety profile and is clinically active. There were no deaths, no DLTs and the only related serious AE was pneumonitis, which occurred after the second dose (after the DLT period) in the highest cohort of $1200 \mathrm{mg}$ Q3W. Overall, the safety results were comparable to the reported safety results from other PD-1i with no new safety signals and no evidence of ADAs [12-14]. There were three radiologically confirmed responses (one CR and two PRs) at $400 \mathrm{mg} \mathrm{Q} 3 \mathrm{~W}$ and 

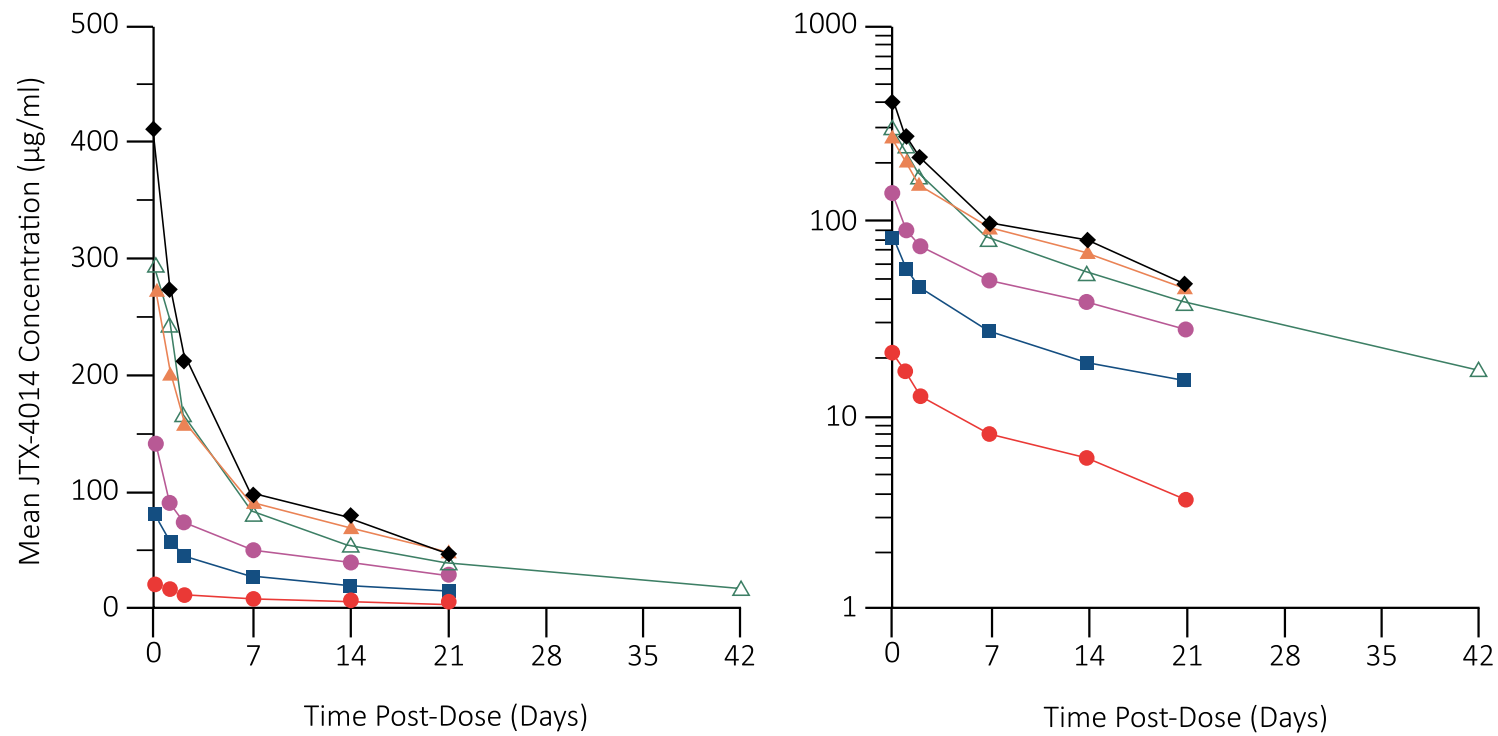

$80 \mathrm{mg} \mathrm{Q3W}$

$240 \mathrm{mg}$ Q3W

$-400 \mathrm{mg}$ Q3W

$-\mathbf{-} 800 \mathrm{mg} \mathrm{Q3W} \triangle 800 \mathrm{mg}$ Q6W

$1200 \mathrm{mg}$ Q3W

Fig. 1 JTX-4014 cycle 1 pharmacokinetics in patients with solid tumors. Mean cycle 1 JTX-4014 concentrations are plotted on a linear (left) and logarithmic (right) scale versus time post-dose

Table 3 Best overall response and overall response rate - safety population

\begin{tabular}{|c|c|c|c|c|c|c|c|}
\hline & $\begin{array}{l}\text { Cohort } 1 \\
(80 \mathrm{mg} \mathrm{Q} 3 \mathrm{~W}) \\
(n=3)\end{array}$ & $\begin{array}{l}\text { Cohort } 2 \\
(240 \mathrm{mg} \text { Q3W) } \\
(n=3)\end{array}$ & $\begin{array}{l}\text { Cohort 3c } \\
(400 \mathrm{mg} \mathrm{Q} 3 \mathrm{~W}) \\
(n=3)\end{array}$ & $\begin{array}{l}\text { Cohort 3a } \\
(800 \mathrm{mg} \text { Q3W }) \\
(n=3)\end{array}$ & $\begin{array}{l}\text { Cohort 3b } \\
(800 \mathrm{mg} \text { Q6W) } \\
(n=3)\end{array}$ & $\begin{array}{l}\text { Cohort } 4 \\
(1,200 \text { mg Q3W) } \\
(n=3)\end{array}$ & $\begin{array}{l}\text { Total } \\
(N=18)\end{array}$ \\
\hline $\begin{array}{l}\text { Best overall } \\
\quad \text { response, } n(\%)\end{array}$ & 0 & 0 & 0 & 0 & 0 & 0 & 0 \\
\hline $\begin{array}{l}\text { Complete } \\
\text { response }\end{array}$ & 0 & 0 & $1(33.3)$ & 0 & 0 & 0 & $1(5.6)$ \\
\hline Partial response & 0 & 0 & $1(33.3)$ & 0 & $1(33.3)$ & 0 & $2(11.1)$ \\
\hline Stable disease & $2(66.7)$ & $(2(66.7)$ & 0 & 0 & $1(33.3)$ & 0 & $5(27.8)$ \\
\hline $\begin{array}{l}\text { Progressive } \\
\text { disease }\end{array}$ & $1(33.3)$ & 0 & $1(33.3)$ & $2(66.7)$ & $1(33.3)$ & $1(33.3)$ & $6(33.3)$ \\
\hline Early termination & 0 & $1(33.3)$ & 0 & $1(33.3)$ & 0 & $2(66.7)$ & $4(22.2)$ \\
\hline $\begin{array}{l}\text { Overall response } \\
\text { rate, } n(\%)\end{array}$ & 0 & 0 & $2(66.7)$ & 0 & $1(33.3)$ & 0 & $3(16.7)$ \\
\hline $\begin{array}{l}95 \% \text { confidence } \\
\text { interval }\end{array}$ & (0.00 to 70.76$)$ & $(0.00,70.76)$ & (89.43 to 99.16 ) & (0.00 to 70.76$)$ & (0.84 to 90.57$)$ & (0.00 to 70.76$)$ & (3.58 to 41.42 ) \\
\hline $\begin{array}{l}\text { Disease control } \\
\text { rate, } n(\%)\end{array}$ & $2(66.7)$ & $2(66.7)$ & $2(66.7)$ & 0 & $2(66.7)$ & 0 & $8(44.4)$ \\
\hline $\begin{array}{l}95 \% \text { confidence } \\
\text { interval }\end{array}$ & (9.43 to 99.16$)$ & (9.43 to 99.16 ) & (9.43 to 99.16$)$ & (0.00 to 70.76$)$ & (9.43 to 99.16 ) & (0.00 to 70.76$)$ & (21.53 to 69.24$)$ \\
\hline
\end{tabular}


Fig. 2 Percent change from baseline in sum of tumor diameter. This figure excludes four patients who did not have a post-baseline scan and two patients who did not have measurable lesions

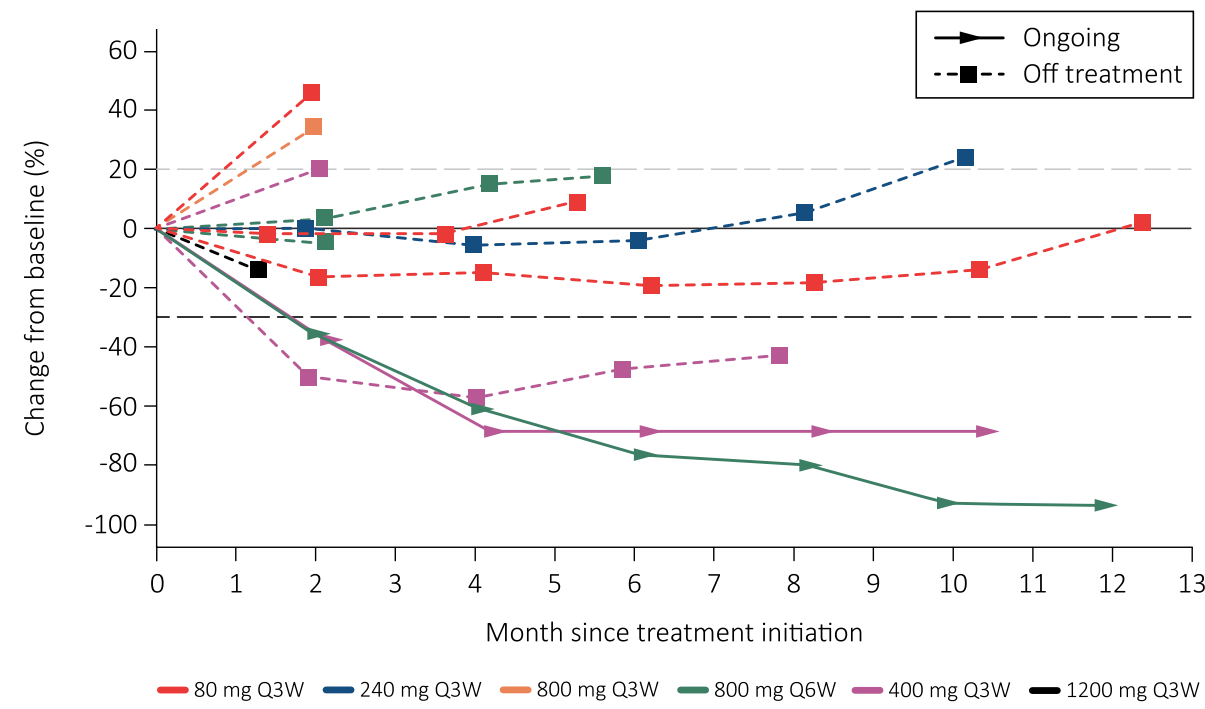

$800 \mathrm{mg}$ Q6W, who all had tumors that stained positive for PD-L1. Based on these safety data and PK modelling, the RP2D was determined to be either $500 \mathrm{mg} \mathrm{Q} 3 \mathrm{~W}$ or $1000 \mathrm{mg}$ Q6W.

A noteworthy finding of our study is the clinical benefit obtained following JTX 4014 treatment in one patient each, with carcinoma ex-pleomorphic adenoma and mucoepidermoid cancer. Both of these rare salivary gland tumors were PD-L1 $>50 \%$ and the patients have durable and ongoing responses. Among salivary tumors, high PD-L1 expression is associated with high-grade tumors and possibly worse clinical outcomes [15-17]. PD-L1 expression in carcinoma ex-pleomorphic adenoma and mucoepidermoid tumors occurs in 10-75\% and 9-57\% of cases, respectively [15-17]. These tumors are not typically responsive to $\mathrm{PD}-1$ inhibition. Of three $\mathrm{PD}-\mathrm{L} 1-$ positive mucoepidermoid cancers enrolled in the KEYNOTE 028 trial and treated with pembrolizumab, none demonstrated reduction in tumor size [18]. Similarly, none of three mucoepidermoid or two carcinoma ex-pleomorphic adenoma patients (of unknown PD-L1 status) had objective responses with pembrolizumab and vorinostat [19].
An additional noteworthy observation in this phase I trial was that, in this population of heavily pre-treated patients with multiple tumor types, the three responders to JTX-4014 had tumors that expressed PD-L1 in tumor types that are not typically PD-Li responsive. This supports the need for predictive biomarkers to select patients from less typically PD-1i responsive tumor types who will respond to a PD- 1 i.

Results of this trial indicate that JTX-4014 may offer clinical benefit to cancer patients as a monotherapy. Furthermore, JTX-4014 may provide an option for combination therapy with other novel agents.

In summary, these data demonstrate that JTX-4014 is well tolerated, with a similar safety profile to that seen with other PD-1is [12-14]. In addition, JTX-4014 was shown to be clinically active in a heavily pre-treated patient population with multiple tumor types. This trial identified two different dosing schedules for the RP2D, which should enable further development of JTX-4014 in combination with innovative cancer therapies. Further study is warranted with innovative combinations and potential predictive biomarkers. 


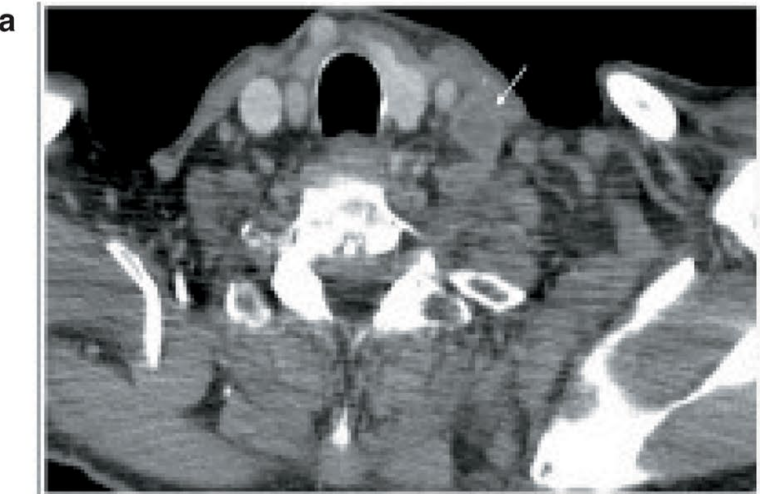

Baseline

Baseline: $5.5 \mathrm{~cm}$

b

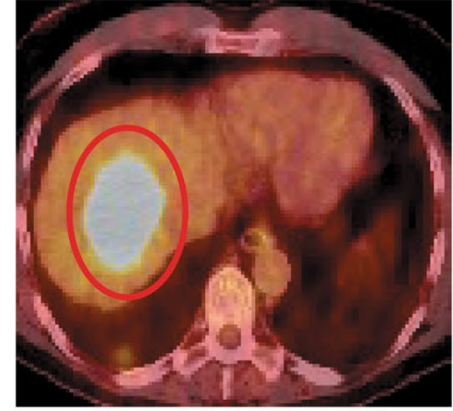

Week 9: $3.7 \mathrm{~cm}$
Week 18
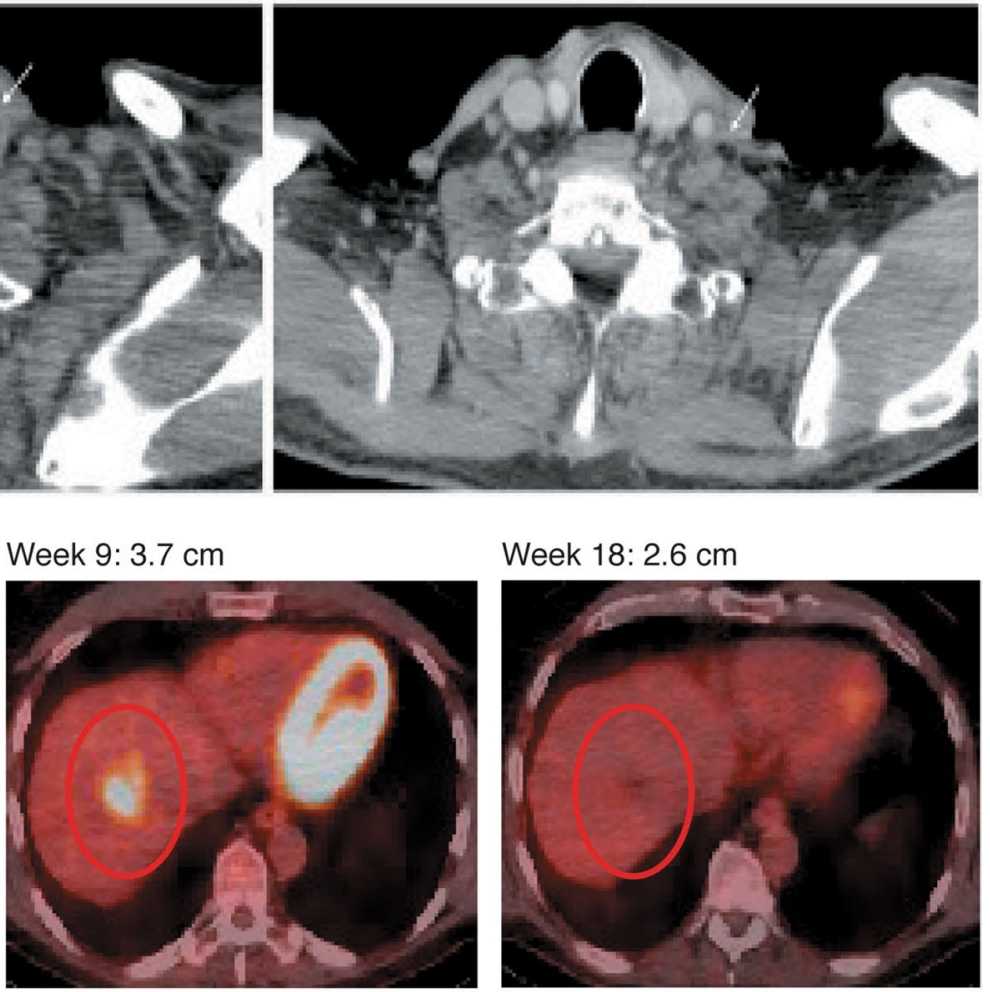

Week 18: $2.6 \mathrm{~cm}$

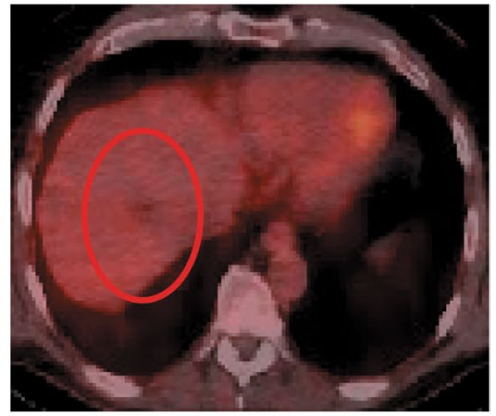

Pre-treatment

C

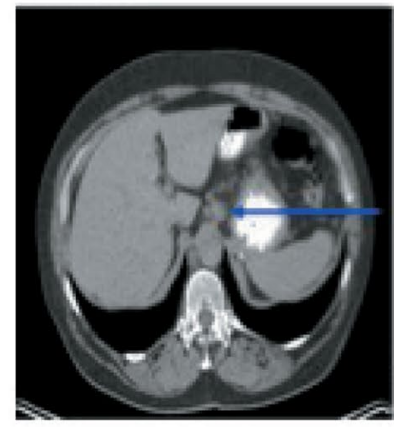

Pre-treatment

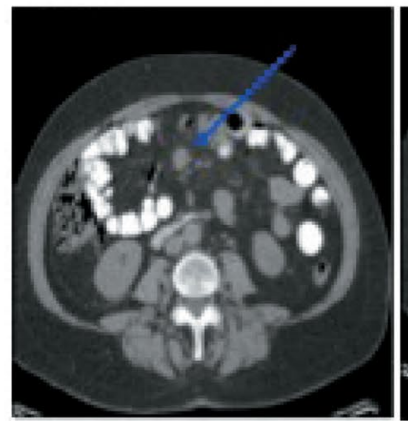

9 Weeks Post-treatment

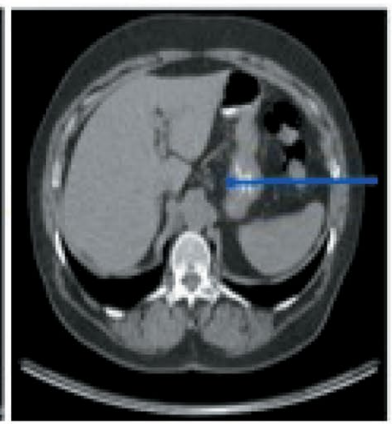

9 Weeks Post-treatment

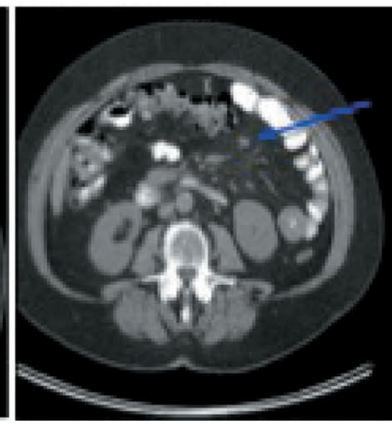

Fig. 3 a Mucoepidermoid carcinoma of the parotid (400 mg Q3W)—confirmed complete response. b Carcinoma ex-pleomorphic adenoma (800 mg Q6W) — confirmed partial response. c Ovarian carcinoma (400 mg Q3W)—confirmed partial response 
Acknowledgements The authors would like to thank the patients and their families, as well as the investigators, co-investigators, and study teams at each of the participating centres.

Author contributions Conception and design: KP.P, NL, GS.F, GR, LL, and JS.W. Development of methodology: KP.P, NL, GS.F, GR, GG, LL, and JS.W. Acquisition of data (provided animals, acquired and managed patients, provided facilities, etc.): KP.P, NL, GS.F, GR, JB, GG, LL, and JS.W. Analysis and interpretation of data (e.g., statistical analysis, biostatistics, computational analysis): JB, KS.B, GG, and JS.W. Writing, review, and/or revision of the manuscript: all authors administrative, technical, or material support (i.e., reporting or organizing data, constructing databases): JB, KS.B, and GG. Study supervision: GR and GG.

Funding This work was funded by Jounce Therapeutics, Inc.

\section{Compliance with ethical standards}

Conflict of interests Baeck J, Brown K.S, Le L, and Riley G are currently employees of Jounce Therapeutics, Inc. Le L also holds stock in Jounce Therapeutics, Inc. prior to employment. Papadopoulos $\mathrm{K}$ received funding to START for conduct of this clinical trial from Jounce Therapeutics, Inc; funding to START for conduct of clinical trials from AbbVie, MedImmune, Daiichi Sankyo, Regeneron, Sanofi, ArQule, other from Amgen, other Calithera Biosciences, Curegenix, Incyte, Merck, Peloton Therapeutics, ADC Therapeutics, 3D Medicines, Formation Biologics, EMD Serono, Syros Pharmaceuticals, Mersana, OncoMed, MabSpace Biosciences and Jounce Therapeutics, Inc.; advisory board fees from Arqule, Basilia and Bayer. Falchook $\mathrm{S}$ has received royalties from Wolters Kluwer, travel fees from Bristol-Myers Squibb, EMD Serono, Fujifilm, Millennium, Sarah Cannon Research institute and has provided an advisory role to Fujifilm and EMD Serono; received research funding from 3-V Biosciences, Abbisko, Abbvie, ADC Therapeutics, Aileron, American Society of Clinical Oncology, Amgen, ARMO, AstraZeneca, BeiGene, Bioatla, Biothera, Celldex, Celgene, Ciclomed, Curegenix, Curis, Cyteir, Daiichi, DelMar, eFFECTOR, Eli Lilly, EMD Serono, Epizyme, Exelixis, Fujifilm, Genmab, GlaxoSmithKline, Hutchison MediPharma, Ignyta, Incyte, Jacobio, Jounce Therapeutics, Inc., Kolltan, Loxo, MedImmune, Millennium, Merck, miRNA Therapeutics, National Institutes of Health, Novartis, OncoMed, Oncothyreon, Precision Oncology, Prelude, Regeneron, Rgenix, Ribon, Strategia, Syndax, Taiho, Takeda, Tarveda, Tesaro, Tocagen, Turning Point Therapeutics, U.T. MD Anderson Cancer Center, Vegenics, Xencor. Lakhani $\mathrm{N}$ has received research funding from Alexion, Apexian, Beigene, Cerulean, Constellation, CytomX, Formation Biologics, Forty Seven, Ikena, Incyte, Innovent Biologics (includes personal fees), Livzon, Lozo, Macrogenics, Merck, Northern Biologics, Odonate Therapeutics, Pfizer, Regeneron, Symphogen, TaiRx. Wang J has received research funding from Acerta Pharma/Astra Zeneca, ADC Therapeutics, Agenus, Aileron Therapeutics, Astra Zeneca (including speaker fees), Astra Zeneva/MedImmune, Bicycle Therapeutics, BioNTech AG, Boehringer Ingelheim, Calithera Biosciences, Celgene, Checkpoint Therapeutics, CicloMed, Clovis Oncology, Curis, Cyteir, Daiichi Sankyo, eFFECTOR Therapeutics, Lilly, EMD Serono, Evelo Therapeutics, Genetech/Roche, Gilead Sciences, GlaxoSmithKline, H3 Biomedicine, Hengrui Pharmaceutical, Hutchinson MediPharma, Ignyta, Incyte, Jacobio, Janssen Research and Development, Jounce Therapeutics, Inc., Klus Pharma Kymab, Loxo, LSK Bipartners, Lycera, Macrogenics, Merck, Millenium Pharmaceuticals, Mirati Therapeutics, Moderna Therapeutics, Pfizer, Phoenix Pharmaceuticals, Placon, Portola Pharmaceuticals, Prelude Therapeutics, QiLu Pharmaceutical, Revolution Medicines, Ribon Therapeutics, Birdie, Syndax, Synthorx, Stemline Therapeu- tics, Taiho Pharmaceutical, Takeda, Tesaro, TopAlliance Biosciences Inc., Vedanta Biosciences, Verastem, Vigeo, Xencor. Gordon G is a paid consultant to Jounce Therapeutics, Inc. and has also been a paid consultant in the last 12 months to Agios, Ayala Pharmaceuticals, Brickell Biotech, FluGen, Heron Therapeutics, Jounce Therapeutics, Inc., OnKure Therapeutics, Prevacept Infection Control, and Zentalis Pharmaceuticals.

Ethics approval and consent to participate This study was conducted in accordance with the International Conference on Harmonisation Good Clinical Practice guidelines and the ethical principles described in the Declaration of Helsinki. Written informed consent was obtained from patients using a form that was approved by the sponsor and the Institutional Review Board/Ethics committee and was in accordance with Good Clinical Practice.

Consent for publication All authors provided consent for publication of this manuscript.

Open Access This article is licensed under a Creative Commons Attribution 4.0 International License, which permits use, sharing, adaptation, distribution and reproduction in any medium or format, as long as you give appropriate credit to the original author(s) and the source, provide a link to the Creative Commons licence, and indicate if changes were made. The images or other third party material in this article are included in the article's Creative Commons licence, unless indicated otherwise in a credit line to the material. If material is not included in the article's Creative Commons licence and your intended use is not permitted by statutory regulation or exceeds the permitted use, you will need to obtain permission directly from the copyright holder. To view a copy of this licence, visit http://creativecommons.org/licenses/by/4.0/.

\section{References}

1. Topalian SL, Drake CG, Pardoll DM (2015) Immune checkpoint blockade: a common denominator approach to cancer therapy. Cancer Cell 27(4):450-461. https://doi.org/10.1016/j.ccell .2015.03.001

2. Lim JS, Soo RA (2016) Nivolumab in the treatment of metastatic squamous non-small cell lung cancer: a review of the evidence. Ther Adv Respir Dis 10(5):444-454. https://doi. org/10.1177/1753465816661091

3. Guo L, Zhang H, Chen B (2017) Nivolumab as programmed death-1 (PD-1) inhibitor for targeted immunotherapy in tumor. J Cancer 8(3):410-416. https://doi.org/10.7150/jca.17144

4. Kwok G, Yau TC, Chiu JW, Tse E, Kwong YL (2016) Pembrolizumab (Keytruda). Hum Vaccin Immunother 12(11):2777-2789. https://doi.org/10.1080/21645515.2016.1199310

5. Warner A, Palmer J, Shoushtari A, Goldman D, Panageas K, Hayes S, Bajwa R, Momtaz P, Callahan M, Wolchook J, Postow M, Chapman P (2020) Long-term outcomes and responses to retreatment in patients with melanoma treated with PD-1 blockade. J Clin Oncol 38(15):1655-1663. https://doi.org/10.1200/ JCO. 19

6. Gauci ML, Lanoy E, Champiat S, Caramella C, Ammari S, Aspeslagh S, Varga A, Baldini C, Bahleda R, Gazzah A, Michot JM, Postel-Vinay S, Angevin E, Ribrag V, Hollebecque A, Soria JC, Robert C, Massard C, Marabelle A (2019) Long-term survival in patients responding to anti-PD-1/PD-L1 therapy and disease outcome upon treatment discontinuation. Clin Cancer Res 25(3):946956. https://doi.org/10.1158/1078-0432.CCR-18-0793 
7. Mittal D, Vijayan D, Smyth MJ (2018) Overcoming acquired PD-1/PD-L1 resistance with CD38 blockade. Cancer Discov 8(9):1066-1068. https://doi.org/10.1158/2159-8290.CD-18-0798

8. Sharma P, Hu-lieskovan S, Wargo JA, Ribas A (2017) Primary, adaptive, and acquired resistance to cancer immunotherapy. Cell 168(4):707-723. https://doi.org/10.1016/j.cell.2017.01.017

9. Wang D, Lin J, Yang X, Long J, Bai Y, Yang X, Mao Y, Sang X, Seery S, Zhao H (2019) Combination regimens with PD-1/ PD-L1 immune checkpoint inhibitors for gastrointestinal malignancies. J Hematol Oncol 12(1):42. https://doi.org/10.1186/s1304 5-019-0730-9

10. Khair DO, Bax HJ, Mele S, Crescioli S, Pellizzari G, Khiabany A, Nakamura M, Harris RJ, French E, Hoffmann RM, Williams IP, Cheung A, Thair B, Beales CT, Touizer E, Signell AW, Tasnova NL, Spicer JF, Josephs DH, Geh JL, MacKenzie Ross A, Healy C, Papa S, Lacy KE, Karagiannis SN (2019) Combining immune checkpoint inhibitors: established and emerging targets and strategies to improve outcomes in melanoma. Front Immunol 10:453. https://doi.org/10.3389/fimmu.2019.00453

11. Hamanishi J, Mandai M, Matsumura N, Abiko K, Baba T, Konishi I (2016) PD-1/PD-L1 blockade in cancer treatment: perspectives and issues. Int J Clin Oncol 21(3):462-473. https://doi. org/10.1007/s10147-016-0959-z

12. Viteri S, Gonzalez-Cao M, Barron F, Riso A, Rosell R (2015) Results of clinical trials with anti-programmed death 1/programmed death ligand 1 inhibitors in lung cancer. Transl Lung Cancer Res 4(6):756-762. https://doi.org/10.3978/j. issn.2218-6751.2015.12.06

13. Naing A, Infante J, Goel S, Burris H, Black C, Marshall S, Achour I, Barbee S, May R, Morehouse C, Pollizzi K, Song X, Steele K, Elgeioushi N, Walcott F, Karakunnel J, LoRusso P, Weise A, Eder J, Curti B, Oberst M (2019) Anti-PD-1 monoclonal antibody MEDI0680 in a phase I study of patients with advanced solid malignancies. J Immunother Cancer 7(1):225. https://doi. org/10.1186/s40425-019-0665-2
14. Carretero-González A, Lora D, Ghanem I, Zugazagoitia J, Castellano D, Sepúlveda J, López-Martin J, Paz-Ares L, de Velasco G (2018) Analysis of response rate with ANTI PD1/PD-L1 monoclonal antibodies in advanced solid tumors: a meta-analysis of randomized clinical trials. Oncotarget 9:8706-8715

15. Mukaigawa T, Hayashi R, Hashimoto K, Ugumori T, Hato N, Fujii S (2016) Programmed death ligand-1 expression is associated with poor disease free survival in salivary gland carcinomas. J Surg Oncol 114(1):36-43. https://doi.org/10.1002/jso.24266

16. Nakano T, Takizawa K, Uezato A, Taguchi K, Toh S, Masuda M (2019) Prognostic value of programed death ligand-1 and ligand-2 co-expression in salivary gland carcinomas. Oral Oncol 90:30-37. https://doi.org/10.1016/j.oraloncology.2019.01.015

17. Vital D, Ikenberg K, Moch H, Rossle M, Huber GF (2019) The expression of PD-L1 in salivary gland carcinomas. Sci Rep 9(1):12724. https://doi.org/10.1038/s41598-019-49215-9

18. Cohen RB, Delord JP, Doi T, Piha-Paul SA, Liu SV, Gilbert J, Algazi AP, Damian S, Hong RL, Le Tourneau C, Day D, Varga A, Elez E, Wallmark J, Saraf S, Thanigaimani P, Cheng J, Keam B (2018) Pembrolizumab for the treatment of advanced salivary gland carcinoma: findings of the phase 1b KEYNOTE-028 Study. Am J Clin Oncol. https://doi.org/10.1097/COC.000000000000042 9

19. Rodriguez CP, Wu QV, Voutsinas J, Fromm JR, Jiang X, Pillarisetty VG, Lee SM, Santana-Davila R, Goulart B, Baik CS, Chow LQM, Eaton K, Martins R (2020) A phase II trial of pembrolizumab and vorinostat in recurrent metastatic head and neck squamous cell carcinomas and salivary gland cancer. Clin Cancer Res 26(4):837-845. https://doi.org/10.1158/1078-0432.CCR-19-2214

Publisher's Note Springer Nature remains neutral with regard to jurisdictional claims in published maps and institutional affiliations. 